\title{
Sitting/standing height ratio in Spanish children from birth to adulthood
}

\author{
Antonio de Arriba Muñoz, M.D..$^{a-c}$, Mercedes Dominguez Cajal, M.D. ${ }^{d}$, \\ Carmen Rueda Caballero, M.D. ', José Ignacio Labarta Aizpún, M.D. ${ }^{a}$, \\ Esteban Mayayo Dehesa, M.D. ${ }^{a}$ and Ángel Ferrández Longás, M.D. ${ }^{c}$
}

\begin{abstract}
Introduction. For the diagnosis of patients with growth disorders, visual inspection and the measurement of body segments may provide important information. The most commonly used method is the assessmentof the sitting/standing height $(\mathrm{SH} / \mathrm{SH})$ ratio and its comparison to aged matched controls.

Objective. To establish the normal values of the sitting/standing height ratio in a normal Aragonese population from birth to 18 years old. Population and Methods.Longitudinal study from birth to 18 years old. Length (up to 3 years old), standing height (as of 2 years old) and sitting height were recorded. Percentiles for sitting/ standing height ratio were determined.

Results. The study included 165 male children and 167 female children. The values of the sitting/standing height ratio decrease from birth both in males and females (0.656 and 0.647, respectively) until the onset of puberty ( 0.514 and $0.519)$; and later start to slightly increase until reaching the definitive adult ratio ( 0.52 and 0.53 , respectively).

Conclusion. Sitting/standing height ratio values are presented in normal male and female children up to 18 years old. This ratio decreases from birth to puberty and then slightly increases until reaching the final adult ratio.

Key words: sitting/standing height, percentile values, body proportions.
\end{abstract}

a. Hospital Miguel Servet, Zaragoza, Spain.

b. Hospital Obispo Polanco, Teruel, Spain.

c. Andrea Prader Research Center, Zaragoza, Spain.

d. Hospital de Barbastro, Barbastro, Spain.

E-mail adress:

Antonio de Arriba

Muñoz M.D.:

adearriba@salud.

aragon.es.

Conflicts of interest: None.

Received: 7-6-2012 Accepted: 11-14-2012 http:/ /dx.doi.org/10.5546/aap.2013.309

\section{INTRODUCTION}

An individual's growth and development are the end result of the interaction between genetic and environmental factors. By acting upon environmental and nutritional factors we can improve the growth of a population, but first we have to learn how such population growths and develops, and this means having normalized standards that may be used as individual and collective controls. ${ }^{1}$

For the diagnosis of short stature patients, visual inspection and the measurement of body segments can provide important information. One of the most commonly used methods for examining body segments consists of estimating the sitting/standing height ratio and comparing it to age matched controls. ${ }^{2}$ Sitting height may even be useful as an approach to total height and development when it becomes difficult to measure them; for example, in the case of patients with lower limb deformities. ${ }^{2}$

Improvements in living conditions, disappearance of infectious diseases and a better availability of nutrients have resulted in a secular acceleration of pediatric populations in developed countries, ${ }^{3-7}$ together with an increase in overweight and obesity rates. ${ }^{8-10}$ Control of children growth is useful for the clinical follow-up of children's health and also as a social indicator of better equity worldwide. ${ }^{11}$ Body proportions show, in addition to the individual variations observed, presumably genetic differences; for example, Asians have shorter lower limbs than Caucasians and, in turn, Caucasians have shorter legs than black people. ${ }^{12}$

There is no information available in Spain regarding body proportions that may serve as a reference for the study of different growth disorders.

\section{OBJECTIVE}

The objective of this study was to establish normal values of the sitting/ standing height ratio in a normal Aragonese population from birth to 18 years old.

\section{POPULATION AND METHODS}

Longitudinal study conducted between 1980 and 2002, as part of the Longitudinal study of growth and development in normal children from 
birth up until adulthood of the Andrea Prader Research Center, Zaragoza, Spain. ${ }^{1}$ It included male and female children from Zaragoza (capital city) and the province of Zaragoza (located in the Autonomous Community of Aragon, in Northeastern Spain). Newborn infants after a normal, term birth, with an Apgar score at $1^{\text {st }}$ minute $\geq 8$ and no symptoms of disease upon the initial examination, from a middle socioeconomic status (as per Graffar's method) were included. The first measurement was done in the first 24 hours of life, most taking place in the first 12 hours. Newborn infants were recruited from, Maternity Center of Hospital Miguel Servet de Zaragoza between 1981 and 1982. The study recruitment phase concluded with 165 boys and 167 girls. No patients with diseases at birth or at follow-up or receiving medications that may have interfered with their growth were included. This was a population followed up by pediatricians at health facilities through the Spanish Children Health Program; children were adequately fed and vaccinated; anthropometric measurements were done once a year (on their birthday date).

Anthropometric data were obtained using precise and adequately calibrated tools. The staff responsible of taking measurements was adequately trained (there were two from 1980 to 1990, and one from 1991 to 2003).Intraobserver and interobserver errors were analyzed; there were no statistically significant differences. The length, height and sitting height measurements were recorded; length at birth was assessed by a single observer using an unstretchable, stiff Masia stadiometer with a $0-70 \mathrm{~cm}$ reading range. During the patient's first three years of life, length was assessed using a Harpenden stadiometer, with a $0.1 \mathrm{~cm}$ precision range; and as from 2 years old, standing height was recorded using an unstretchable, $60-210 \mathrm{~cm}$ stiff wall stadiometer with a $0.1 \mathrm{~cm}$ precision range. Measures were always recorded in the morning, between $10 \mathrm{am}$ and $1 \mathrm{pm}$. For the measurement of height, the child was placed in a dorsal recumbent position, with his/her head slightly stretched, the palm of the hands over the ears with the thumbs on the parietal bones and the rest of the fingers on the temporal-occipital region. The head was positioned in such a manner that the eyes plane was parallel to the floor or ceiling while standing, or perpendicular to the floor or ceiling while lying down. For the measurement of horizontal height, the limit was the sole of the left foot. In all cases, the platform was moved to the maximum limit several times until a definitive value was obtained. For the measurement of the sitting height the same measurement tools were used, with the vertex as one limit and the child's buttocks in a dorsal recumbent position as the other limit against the moving platform, from birth up to 3 years old, and in a sitting position from 3 years old onwards. Up to 3 years old the crown-rump length was measured, which reflects the trunk length, which is conceptually similar to the sitting height while the child is in a dorsal recumbent position on the measurement table.

The LMS method described by Cole, et al. ${ }^{13-15}$ was used to construct normalized growth standards by estimating reference centile curves. For data analysis, the SPSS v18 (Statistical Package for the Social Sciences) software was used.

The study was conducted in accordance with the renowned deontological standards included in the Declaration of Helsinki, the Good Clinical Practice standards and in compliance with the Spanish laws in force regarding biomedical research involving human beings. The project was reviewed by the Research Commission of Hospital Miguel Servet de Zaragoza. The study was explained in detail to the child's father/ mother/legal guardian and they were asked to sign the informed consent form, and for children older than 8 years old their assent was requested to continue in the study. Data are protected from unauthorized use by people outside this investigation and will be kept confidential.

\section{RESULTS}

Initially, 165 male children and 167 female children were included, in whom annual measurements would be performed on the date of their birthday. However, as of the first year of the study there were dropouts; most of them of children who lived in the region and had to travel to the capital city for the examination, and this situation was on and on every year. Therefore, 74 male children and 93 female children were studied up to 18 years old. Tables 1 and 2 show the yearly variation in the study regarding the number of patients.

Table 1 shows mean, standard deviation (SD) and sitting/standing height ratio percentile valuesin male children; Table 2 shows the same values for female children. The tables were prepared based only on the 74 boys and 93 girls that completed the study; data overlap with those obtained in previous tables.

Figure 1 represents the percentile distribution 
of the sitting/standing height ratio in males from birth up to 18 years old, while Figure 2 shows the same values for females.

There is a decrease in sitting/standing height ratio values from birth to the onset of puberty (approximately 11 years old in girls and 12 years old in boys) and they increase slightly from that moment until reaching a definitive adult height. Thus, this study shows that, at birth, trunk length is longer than lower limbs length; as years go by growth over the first few years mostly depends on the limbs, while the effect of trunk growth

TABLE 1. Normal longitudinal values in sitting/standing height ratio from birth to adulthood in male childrens

\begin{tabular}{|c|c|c|c|c|c|c|c|c|c|c|}
\hline Age & $\mathbf{N}$ & Mean & SD & P3 & P10 & P25 & P50 & P75 & P90 & P97 \\
\hline 0 & 165 & 0.653 & 0.007 & 0.64 & 0.649 & 0.650 & 0.656 & 0.659 & 0.66 & 0.666 \\
\hline 1 & 154 & 0.629 & 0.005 & 0.619 & 0.622 & 0.628 & 0.629 & 0.634 & 0.635 & 0.639 \\
\hline 2 & 126 & 0.597 & 0.005 & 0.587 & 0.59 & 0.594 & 0.597 & 0.599 & 0.605 & 0.607 \\
\hline 3 & 137 & 0.579 & 0.005 & 0.57 & 0.574 & 0.576 & 0.578 & 0.579 & 0.582 & 0.587 \\
\hline 4 & 134 & 0.57 & 0.004 & 0.562 & 0.568 & 0.569 & 0.57 & 0.571 & 0.572 & 0.578 \\
\hline 5 & 133 & 0.559 & 0.004 & 0.552 & 0.554 & 0.558 & 0.56 & 0.562 & 0.564 & 0.567 \\
\hline 6 & 136 & 0.551 & 0.004 & 0.543 & 0.545 & 0.549 & 0.551 & 0.553 & 0.556 & 0.559 \\
\hline 7 & 128 & 0.544 & 0.004 & 0.536 & 0.538 & 0.54 & 0.543 & 0.547 & 0.549 & 0.552 \\
\hline 8 & 128 & 0.531 & 0.004 & 0.523 & 0.525 & 0.527 & 0.53 & 0.533 & 0.536 & 0.539 \\
\hline 9 & 124 & 0.524 & 0.004 & 0.516 & 0.519 & 0.522 & 0.524 & 0.527 & 0.53 & 0.532 \\
\hline 10 & 121 & 0.519 & 0.004 & 0.511 & 0.514 & 0.518 & 0.52 & 0.522 & 0.524 & 0.526 \\
\hline 11 & 119 & 0.514 & 0.004 & 0.507 & 0.509 & 0.511 & 0.514 & 0.515 & 0.52 & 0.522 \\
\hline 12 & 121 & 0.514 & 0.004 & 0.507 & 0.509 & 0.511 & 0.514 & 0.515 & 0.52 & 0.522 \\
\hline 13 & 116 & 0.514 & 0.005 & 0.504 & 0.506 & 0.51 & 0.514 & 0.517 & 0.521 & 0.524 \\
\hline 14 & 111 & 0.516 & 0.005 & 0.506 & 0.508 & 0.512 & 0.516 & 0.519 & 0.522 & 0.525 \\
\hline 15 & 106 & 0.519 & 0.005 & 0.508 & 0.51 & 0.514 & 0.519 & 0.522 & 0.525 & 0.528 \\
\hline 16 & 93 & 0.519 & 0.005 & 0.509 & 0.511 & 0.515 & 0.519 & 0.522 & 0.526 & 0.529 \\
\hline 17 & 80 & 0.522 & 0.005 & 0.512 & 0.515 & 0.519 & 0.522 & 0.526 & 0.529 & 0.532 \\
\hline 18 & 74 & 0.523 & 0.005 & 0.514 & 0.517 & 0.52 & 0.523 & 0.527 & 0.53 & 0.533 \\
\hline
\end{tabular}

$\mathrm{N}$ : sample size. SD: standard deviation. P: percentile.

TABLE 2. Normal longitudinal values in sitting/standing height ratio from birth to adulthood in female children

\begin{tabular}{|c|c|c|c|c|c|c|c|c|c|c|}
\hline Age & $\mathbf{N}$ & Mean & SD & P3 & P10 & P25 & P50 & P75 & P90 & P97 \\
\hline 0 & 167 & 0.647 & 0.005 & 0.637 & 0.639 & 0.642 & 0.647 & 0.65 & 0.653 & 0.657 \\
\hline 1 & 156 & 0.604 & 0.005 & 0.594 & 0.597 & 0.601 & 0.603 & 0.607 & 0.61 & 0.614 \\
\hline 2 & 133 & 0.592 & 0.005 & 0.582 & 0.585 & 0.589 & 0.593 & 0.596 & 0.599 & 0.602 \\
\hline 3 & 136 & 0.575 & 0.005 & 0.566 & 0.57 & 0.572 & 0.574 & 0.578 & 0.581 & 0.585 \\
\hline 4 & 133 & 0.565 & 0.005 & 0.556 & 0.559 & 0.562 & 0.564 & 0.567 & 0.571 & 0.575 \\
\hline 5 & 126 & 0.556 & 0.005 & 0.547 & 0.549 & 0.552 & 0.555 & 0.559 & 0.562 & 0.566 \\
\hline 6 & 129 & 0.547 & 0.005 & 0.538 & 0.54 & 0.544 & 0.548 & 0.55 & 0.553 & 0.556 \\
\hline 7 & 124 & 0.541 & 0.005 & 0.531 & 0.533 & 0.536 & 0.54 & 0.543 & 0.547 & 0.551 \\
\hline 8 & 123 & 0.535 & 0.005 & 0.525 & 0.528 & 0.531 & 0.534 & 0.537 & 0.54 & 0.545 \\
\hline 9 & 123 & 0.53 & 0.005 & 0.521 & 0.524 & 0.527 & 0.53 & 0.533 & 0.537 & 0.54 \\
\hline 10 & 121 & 0.523 & 0.005 & 0.513 & 0.516 & 0.52 & 0.523 & 0.526 & 0.53 & 0.533 \\
\hline 11 & 121 & 0.519 & 0.005 & 0.509 & 0.512 & 0.516 & 0.52 & 0.523 & 0.527 & 0.529 \\
\hline 12 & 121 & 0.518 & 0.005 & 0.508 & 0.51 & 0.515 & 0.519 & 0.523 & 0.526 & 0.528 \\
\hline 13 & 114 & 0.522 & 0.005 & 0.512 & 0.515 & 0.519 & 0.522 & 0.525 & 0.529 & 0.532 \\
\hline 14 & 112 & 0.525 & 0.005 & 0.515 & 0.518 & 0.522 & 0.525 & 0.528 & 0.532 & 0.535 \\
\hline 15 & 106 & 0.527 & 0.005 & 0.517 & 0.52 & 0.524 & 0.527 & 0.528 & 0.533 & 0.537 \\
\hline 16 & 101 & 0.529 & 0.005 & 0.52 & 0.522 & 0.526 & 0.529 & 0.532 & 0.536 & 0.538 \\
\hline 17 & 95 & 0.529 & 0.005 & 0.52 & 0.522 & 0.526 & 0.53 & 0.533 & 0.536 & 0.539 \\
\hline 18 & 93 & 0.53 & 0.006 & 0.52 & 0.523 & 0.527 & 0.53 & 0.534 & 0.537 & 0.54 \\
\hline
\end{tabular}

N: sample size. SD: standard deviation. P: percentile. 
is more significant throughout puberty until reaching an adult height.

\section{DISCUSSION}

This study provides reference values for the
Spanish population in relation to the sitting/ standing height ratio, which is 0.65 at birth and 0.51 at the onset of puberty. This indicates that pre-puberty growth in children mostly depends on the limbs length instead of the

FIGURE 1. Normal longitudinal values in sitting/standing height ratio as per percentile values from birth to adulthood in male children

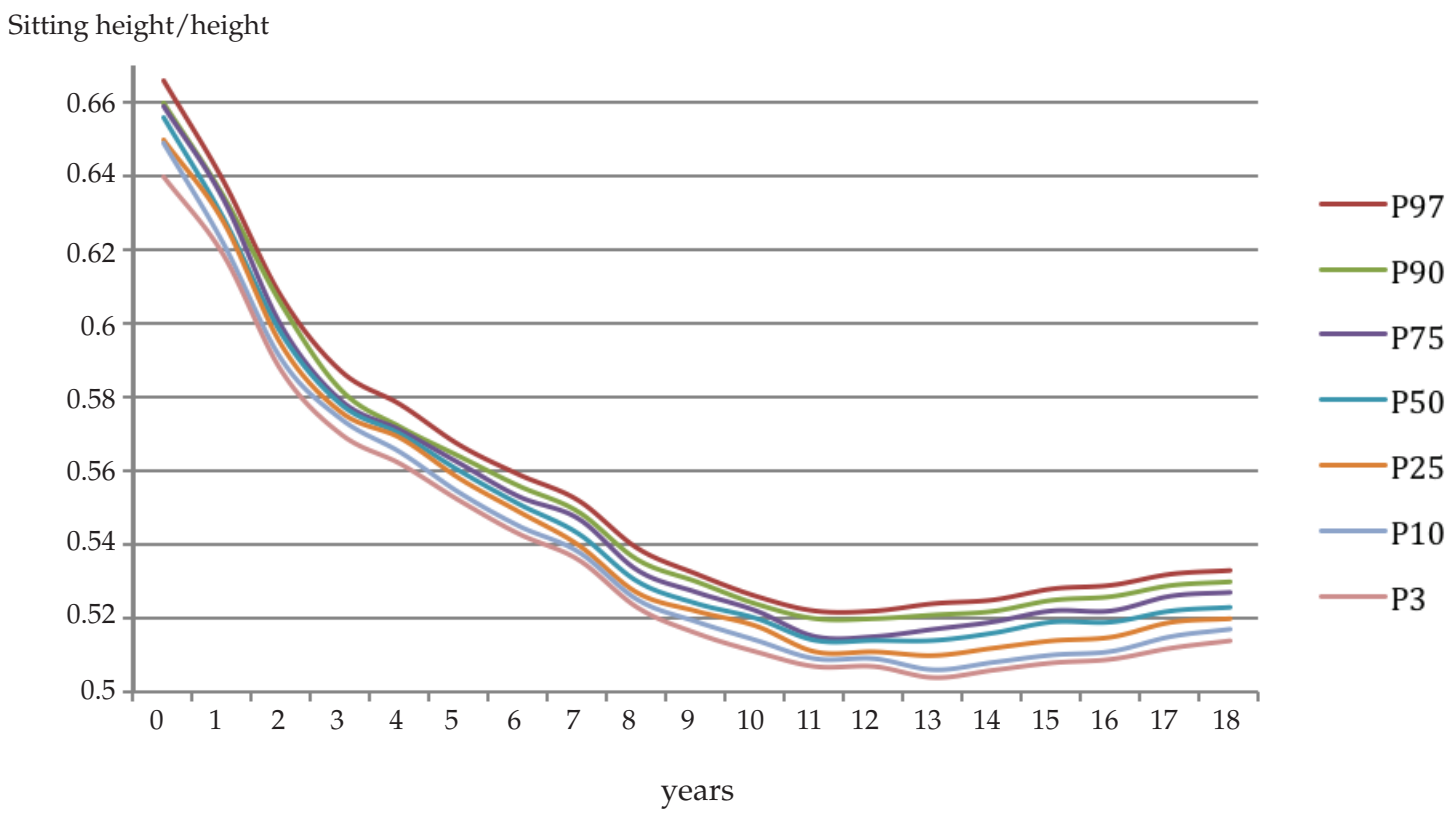

FIGURE 2. Normal longitudinal values in sitting/standing height ratio as per percentile values from birth to adulthood in female children

Sitting height/height

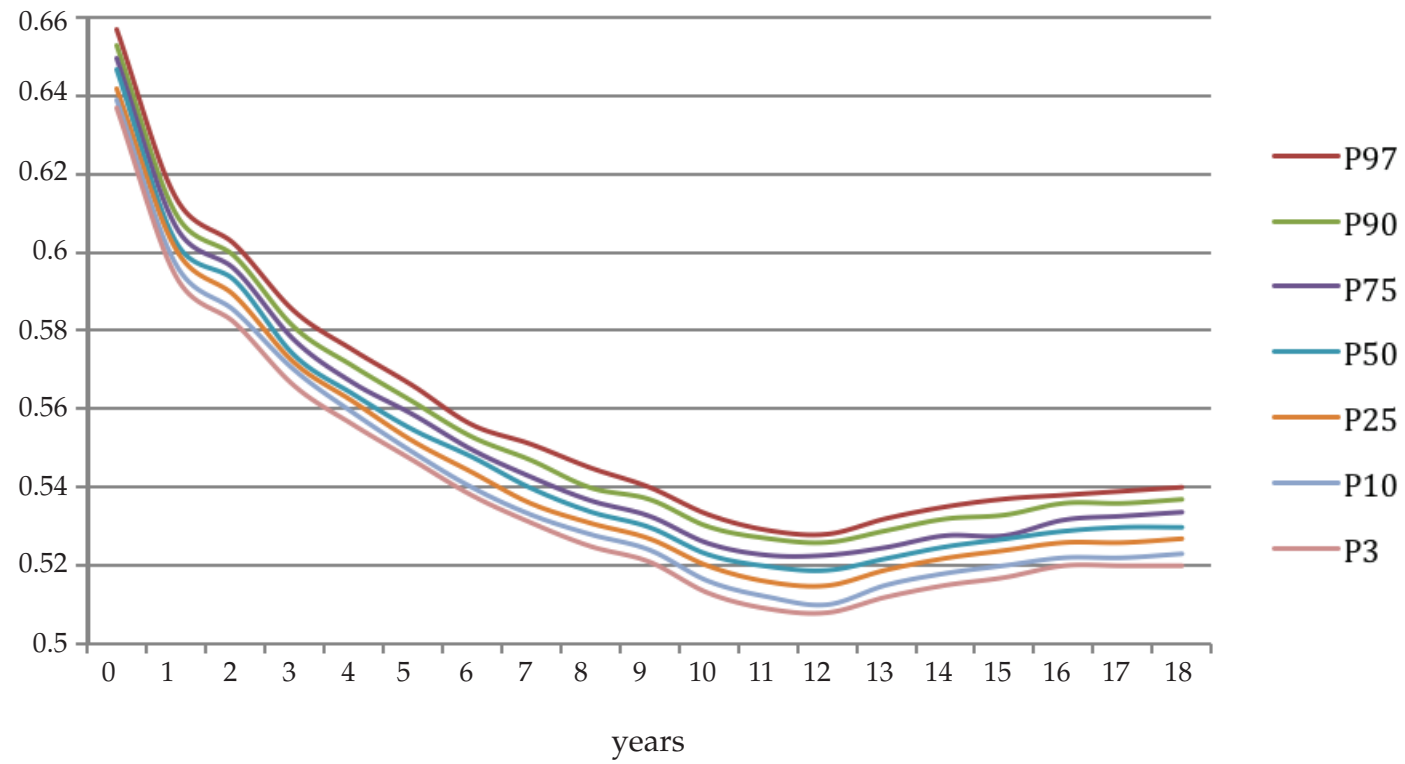


trunk length. Over the last decades, interest has grown about children's growth and development and the height of populations, not only among healthcare workers, but also among historians and economists. Several Spanish studies ${ }^{7}$ have analyzed the evolution of height over the past century. It has been confirmed that there is a positive secular acceleration, which has increased over the past 50 years and is related to improved economic and socio-sanitary conditions. Adult height in males has increased approximately $14 \mathrm{~cm}$ over the last century, being about $177 \mathrm{~cm}$ at present. Such positive secular growth is mostly due to an increase in limbs length rather than that of the trunk. ${ }^{16-18}$

The values obtained in this study were very similar to those of a German cross-sectional study conducted by Fredicks, et al. ${ }^{2}$ in 6877 boys and 6202 girls from birth to 21 years old, between 1996 and 1997.

Eveleth and Tanner ${ }^{12}$ reported that the differences in body proportions were genetically controlled and varied among European, African and Asian populations (Caucasians have a higher height, with longer lower limbs when compared to Asians). An improvement in environmental conditions results in a longer limb length in all ethnic groups. It has been stated that monitoring the length of limbs is most effective than measuring total height for the evaluation of environmental improvements in the population. As described by Wales, et al., ${ }^{19}$ abused children have relatively shorter limbs and show a significant height catch-up after their social environment improves. ${ }^{19}$

The charts herein included may be useful for the diagnosis of patients with growth disorders, both in relation to a short or a high stature, because it is known that tall patients have relatively long lower limbs and vice versa. ${ }^{2}$ The most common reason to seek consultation in pediatric endocrinology is short stature, both in boys and girls, and it is a condition for which pediatric endocrinologists are extensively trained. However, there are children of short stature with a difficult diagnosis, because it is not frequent, in whom the measurement of their body proportions may be useful at the time of making a diagnosis; for example, most patients with chondrodysplastic syndromes (bone dysplasias) typically have short limbs. These conditions include hypochondroplasia, which is hard to diagnose and is characterized by a disproportionate short stature, relatively short lower limbs, macrosomia and lumbar lordosis. SHOX gene haploinsufficiency produces a disproportionate short stature with mesomelia, limb deformity (Madelung deformity being the most common one), scoliosis or micrognathia. ${ }^{20-}$ ${ }^{22}$ There are other conditions, such as Down's syndrome or Turner's syndrome, which also present with altered body proportions.

Other diseases are associated with a short trunk compared to limbs; in children with a high stature it is important to distinguish between Marfan's syndrome, gonadotropin deficiency or Klinefelter's syndrome at the time of diagnosis given the clinical consequences of each condition. Marfan's syndrome is characterized by a disproportionate high stature with relatively long lower limbs and the measurement of body proportions may help for diagnosis. ${ }^{2}$

Tanner charts, ${ }^{23,24}$ which were developed in 1965 for British children, are commonly used in Argentina. The purpose for conducting this study was to obtain updated data for the Spanish population, specifically for Aragonese children.

For this reason, it would be interesting to include body segment measurements into routine exams during the office visit because they may provide a lot of information that can be of vital importance for the diagnosis, either in the case of short or high stature.

\section{CONCLUSION}

The present study shows the values of the sitting/standing height ratio in normal female and male children up to 18 years old. This ratio decreases from birth to puberty and then slightly increases until reaching a final adult ratio.

\section{REFERENCES}

1. Ferrández Longás A, Baguer L, Labarta JI, Labena C, Mayayo E, Puga B, et al. Longitudinal study of normal spanish children from birth to adulthood anthropometric, puberty, radiological and intellectual data. Pediatr Endocrinol Rev 2005;2(Suppl 4):423-642.

2. Fredicks AM, van Buuren S, van Heel WJM, DijkmanNeerincx RHM, et al. Nationwide age references for sitting height, leg length, and sitting height/height ratio, and their diagnostic value for disproportionate growth disorders. Arch Dis Child 2005;90:807-12.

3. Hesse V, Voigt M, Sälzler A, Steinberg S, et al. Alterations in height, weight, and body mass index of newborns, children, and young adults in eastern germany after german reunification. J Pediatr 2003;142:259-62.

4. Deheeger M, Rolland-Cachera MF. Étude longitudinale de la croissance d'enfants parisiens suivis de l'âge de 10 mois à 18 ans. Arch Pediatr 2004;11:1130-44.

5. Carrascosa A, Yeste D, Copil A, Gussinyé M. Aceleración secular del crecimiento. Valores de peso, talla e índice de masa corporal en niños, adolescentes y adultos jóvenes de 
la población de Barcelona. Med Clin (Barc) 2004;123:445-51.

6. Del Río Navarro BE, Velázquez-Monroy O, Santos Preciado JI, Lara-Esqueda A, Berber A, et al. Mexican anthropometric percentiles for ages 10-18. Eur J Clin Nutr 2007;61:963-75.

7. Carrascosa A, Fernández JM, Fernández C, Ferrández A, et al. Estudio transversal español de crecimiento 2008. Parte II: valores de talla, peso e índice de masa corporal desde el nacimiento a la talla adulta. An Pediatr (Barc) 2008;68:552-69.

8. Bua J, Olsen LW, Sorensen TI. Secular trends in childhood obesity in Denmark during 50 years in relation to economic growth. Obesity 2007;15:977-85.

9. Aranceta J, Pérez-Rodrigo C, Serra-Majen L, Bellido D, et al. Prevention of overweight and obesity: A Spanish approach. Public Health Nutr 2007;10:1187-93.

10. Carrascosa A. Obesidad durante la infancia y adolescencia. Una pandemia que reclama nuestra atención (Editorial). Med Clin (Barc) 2006;126:693-4.

11. Sánchez E, Carrascosa A, Fernández JM, Ferrández A, et al. Estudios españoles de crecimiento: situación actual, utilidad y recomendaciones de uso. An Pediatr (Barc) 2011;74(3):193.e1-193.e16.

12. Eveleth PB, Tanner JM. Worldwide variation in human growth. Cambridge: Cambridge University Press; 2000. Pág.186.

13. Cole TJ. The LMS method for constructing normalized growth standards. Eur J Clin Nutr 1990;44:45-60.

14. Cole TJ. The international growth standard for preadolescents and adolescent children: Statistical considerations. Food Nutr Bull 2006;27:S237-43.
15. Cole TJ, Flegal KM, Nicholls D, Jackson AA. Body mass index to define thinness in children and adolescent: International survey. BJM 2007;335:166-7.

16. Bogin B, Smith P, Orden AB. Rapid change in height and body proportions of Maya American children. Am J Hum Biol 2002;14:753-61.

17. Dangour AD, Schilg S, Hulse JA. Sitting height and subisquial length centile curves for boys and girls from Southeast England. Ann Hum Biol 2002;29:290-305.

18. Tanner JM. Principles of growth standars. Acta Paediatr Scand 1990;79:963-7.

19. Wales JK, Herber SM, Taizt LS. Height and body proportions in children abuse. Arch Dis Child 1992;67:632-5.

20. Huber C, Rosilio M, Munnich A, Cormier-Daire V. High incidence of SHOX anomalies in individuals with short stature. J Med Genet 2006;43:735-9.

21. Rappold G, Blum W, Shavrikova E, Crowe B, et al. Genotypes and phenotypes in children with short stature: clinical indicators of SHOX haploinsufficiency. J Med Genet 2007;44:306-13.

22. Binder G. ShortStature due to SHOX deficiency: genotype, phenotype and therapy. Horm Res Paediatr 2011;75:81-9.

23. Tanner JM, Whitehouse RH, Takaishi M. Standards from birth to maturity for height, weight, height velocity, and weight velocity: British children, 1965. Part I. Arch Dis Childh 1966;41:454-71.

24. Tanner JM, Whitehouse RH, Takaishi M. Standards from birth to maturity for height, weight, height velocity, and weight velocity: British children, 1965. Part II. Arch Dis Childh 1966;41:613-35. 